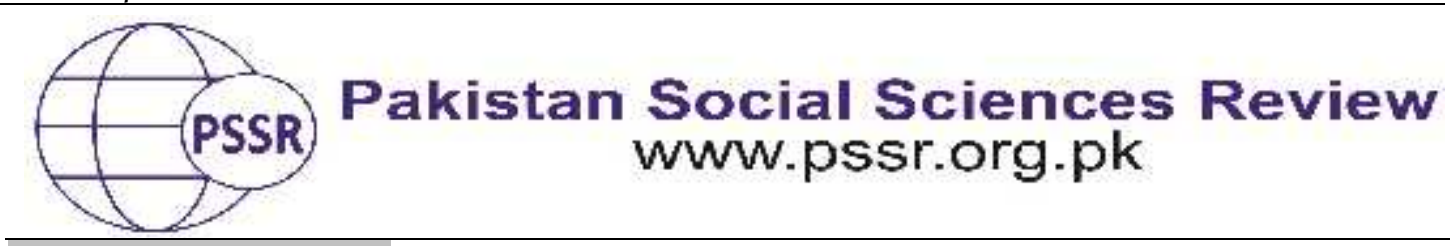

RESEARCH PAPER

\title{
Existence of Glass Ceiling in Structures and Gender Forms in the Universities of Pakistan
}

\author{
Saima Afzal ${ }^{1}$ Dr. Aaisha Akar ${ }^{2}$
}

1. Ph. D Scholar, EPM Department, Allama Iqbal Open University, Islamabad, Pakistan

2. Professor, Department of Education, Allama Iqbal Open University, Islamabad, Pakistan

\begin{tabular}{|c|c|}
\hline PAP & ABSTR \\
\hline $\begin{array}{l}\text { Received: } \\
\text { May 28, } 2020 \\
\text { Accepted: } \\
\text { August 25, } 2020 \\
\text { Online: } \\
\text { September } 15,2020\end{array}$ & $\begin{array}{l}\text { In this study, the existence of the glass ceiling has been } \\
\text { analyzed in the Federal Chartered universities of Pakistan. } \\
\text { The study was descriptive. The data was collected through } \\
\text { questionnaires from the employees of the universities, using } \\
\text { purposive sampling techniques }(n=484) \text {. The data revealed }\end{array}$ \\
\hline $\begin{array}{l}\text { Keywords: } \\
\text { Federal Chartered } \\
\text { Universities, } \\
\text { Gender } \\
\text { Glass Ceiling, } \\
\text { Organizational } \\
\text { Structure }\end{array}$ & $\begin{array}{l}\text { that the glass ceiling exists in Federal Chartered Universities } \\
\text { of Pakistan. Elements of glass ceiling such as gender biases } \\
\text { and internal structure of organizations were found to exist. } \\
\text { Gender-based glass ceiling was found to exist for women and } \\
\text { not for men. The internal structures factor favors the males. } \\
\text { Based on discussions with the respondents, the strategies for }\end{array}$ \\
\hline $\begin{array}{l}\text { Corresponding } \\
\text { Author }\end{array}$ & $\begin{array}{l}\text { melting the glass ceiling have been proposed. It has been } \\
\text { recommended that the researchers may replicate this research } \\
\text { to other industries. Further, it has been recommended that the } \\
\text { practitioners can implement the strategies to mitigate the } \\
\text { glass ceiling in their organizations }\end{array}$ \\
\hline
\end{tabular}

\section{Introduction}

There are hindrances for certain groups of people to reach the top level of management due to factors such as gender, race, and organizational policies. Glass Ceiling encompasses this phenomenon; which hinders minority groups (including women) seeking promotions. Glass ceiling is pervasive in organizations across countries (Kim et al., 2015).Empirical evidence supports the existence of different elements of Glass Ceiling in different countries such as Australia(Davidson, 2009; Maginn, 2010; Still, 2006), China (Tan, 2008), France (Barnet-Verzat \& Wolff, 2008), South Africa (Booysen \& Nkomo, 2010; Mathur-Helm, 2006), United Kingdom (Davidson, 2009)and United States (Eagly \& Carli, 2007). In Pakistan, the workforce has diversified, but we seldom come across an organization that is headed by a 
woman (Saleem et al., 2017). For instance, in Islamabad, there is no female head of a university. Only Quaid-e-Azam University once had a female vice-chancellor. There are different elements of glass ceiling thatdo not allow minorities to the top positions/managerial positions.

This study is an endeavor to address the problem of glass ceiling. The objectives of the study are 1) to find out if the glass ceiling exists in Federal Chartered Universities of Pakistan, 2) to identify the existence of different elements of glass ceiling in Federal Chartered Universities of Pakistan and 3) to suggest the measures and strategies to melt the glass ceiling. We have used the definition by Boyd (2008) to operationalize glass ceiling, which is "The unnatural hindrance which has an attitudinal or organizational bend on any side. The bend that does not let qualified individuals from going vertical in their organization". We have operationalized Federal Chartered University as a university, or an institute which has been chartered by the federal government of a country that is it has been established with the approval and under the applicable law(s) of the concerned government is known as federal chartered university. The taste-based discrimination theory by Becker (2010) supports the conceptual model presented in this research. According to the theory, the labor market discrimination is a phenomeno nin which the discrimination is done while hiring and promotion activities based on the preferences of management instead of merit. The preferences can be based on cultures, different religious thoughts, areas, and others(Becker, 1993, 1996, 2009, 2010; Fortin, 2005).

\section{Literature Review}

\section{Glass Ceiling}

Globally there are hindrances for different groups of people to reach the top level of the management. Such hindrances can be racial, language-based, genderbased, regional prejudice based etc. (Commission, 1995). Working women are facing the male dominance all around the world. The phenomenon of glass ceiling surfaced from the seminal work of Sappho from Greece, Hildegard of Bingen, and Jane Austen as the pioneers of the "Feminist Movement."At the start, the glass ceiling was only focused on marginalizing females at the workplace. Still, later it was broadened to the hindrance of promotion and was defined as "Glass ceiling is a subtle hindrance in an organization that does not allow women or minorities to go vertical in their professional life."In Pakistan, women are deprived and underrepresented on gender basis (Siraj \& Sadiq, 2016). Many countries are taking glass ceiling as a dire situation professionally, but the situation in Pakistanis still bleak and dark, and further work is required to address this problem (Siraj \& Sadiq, 2016).

Hypothesis: Glass Ceiling exists in Federal Chartered Universities of Pakistan. 


\section{Gender and Glass Ceiling}

In recent years, the amount of literature on women's leadership has increased; however, few studies explore the glass ceiling in the higher education sector. Muchof the literature has been limited to the traditionally defined views of feminism. Women in education at Higher education level have not been given the due importance(Carnes et al., 2008; Deem, 2005; Williams, 2005) in this regard. Traces do exist in literature in which research has been conducted in which women in leadership positions in higher education and other leadership roles (Byrd, 2009; Williams, 2005) have been studied, but the majority of the studies focused on the barriers for equal access for the opportunity to excel. The missing aspect was the individual experiences for upward hindrances. As a result, there is a marked absence of research on how women experience the glass ceiling in higher education and that too in Pakistan. This research focuses on filling this gap in the literature.

Women, when globally compared to men, find many barriers to have managerial positions. They were found quite less in number than men at higher positions and found concentrating at lower and middle levels (Northouse, 2018). Valian(1998)pointed out that discriminatory treatment exists in almost all professions like business, sports, military, academics, and politics. Although women constitute fifty percent of the workforce, but there is visible discrimination in wages, promotion, and placements(Cardoso \& Winter-Ebmer, 2010). Despite being qualified and men are superseding experienced women. They are being paid less than men (Anh, 2018; Arulampalam et al., 2007; Barnet-Verzat \& Wolff, 2008; Cardoso \& Winter-Ebmer, 2010; Khanna, 2012). To achieve success in the workplace, women have to accept the male dominating valued culture (Eagly \& Carli, 2007).Business and corporate policies are stereotypes with no diversity in them as they encourage male higher-level positions(Lockwood, 2004). Holding women at a leadership place can create many problems as the women as a leader is not being accepted by males(Bosse \& Taylor III, 2012; Mathur-Helm, 2006; Ng \& Sears, 2017). It is a pervasive thought about women that gender differences between male and female makes it difficult to the extent of impossible for women to play a leadership role(Cook \& Glass, 2014; Saleem et al., 2017).Therefore, based on the literature review and substantial empirical evidence, the following hypothesis is proposed.

Hypothesis: Gender is attributed to Glass Ceiling at Federal Chartered Universities of Pakistan.

\section{Social Internal Structure of the Organization and Glass Ceiling}

According to Parker and Fagenson (1994), women themselves consider racism and not the gender sexism as the most significant hindrance for availing the opportunities. Pakistan is a patriarchal society. In which society accepts male dominance over female dominance. Therefore, it is challenging for many of the people to accept or, for that matter, promote the female employees to management 
level. Very few studies have so far been conducted to study how race/provincialism affects leadership in an organization(Parker \& Fagenson, 1994; Siraj \& Sadiq, 2016).

Females have the necessary knowledge, skills, and abilities as laid down by the job description of the managerial position. However, the organizations are not used to hire women(Cook \& Glass, 2014; Eagly \& Carli, 2007).Even, if the women are promoted to the next managerial level, there is a significant pay gap. For instance, in Pakistan, a study by Sharjeel Saleem et al. (2017) revealed that there is a significant pay gap between the pays of male and female managers in Pakistan.

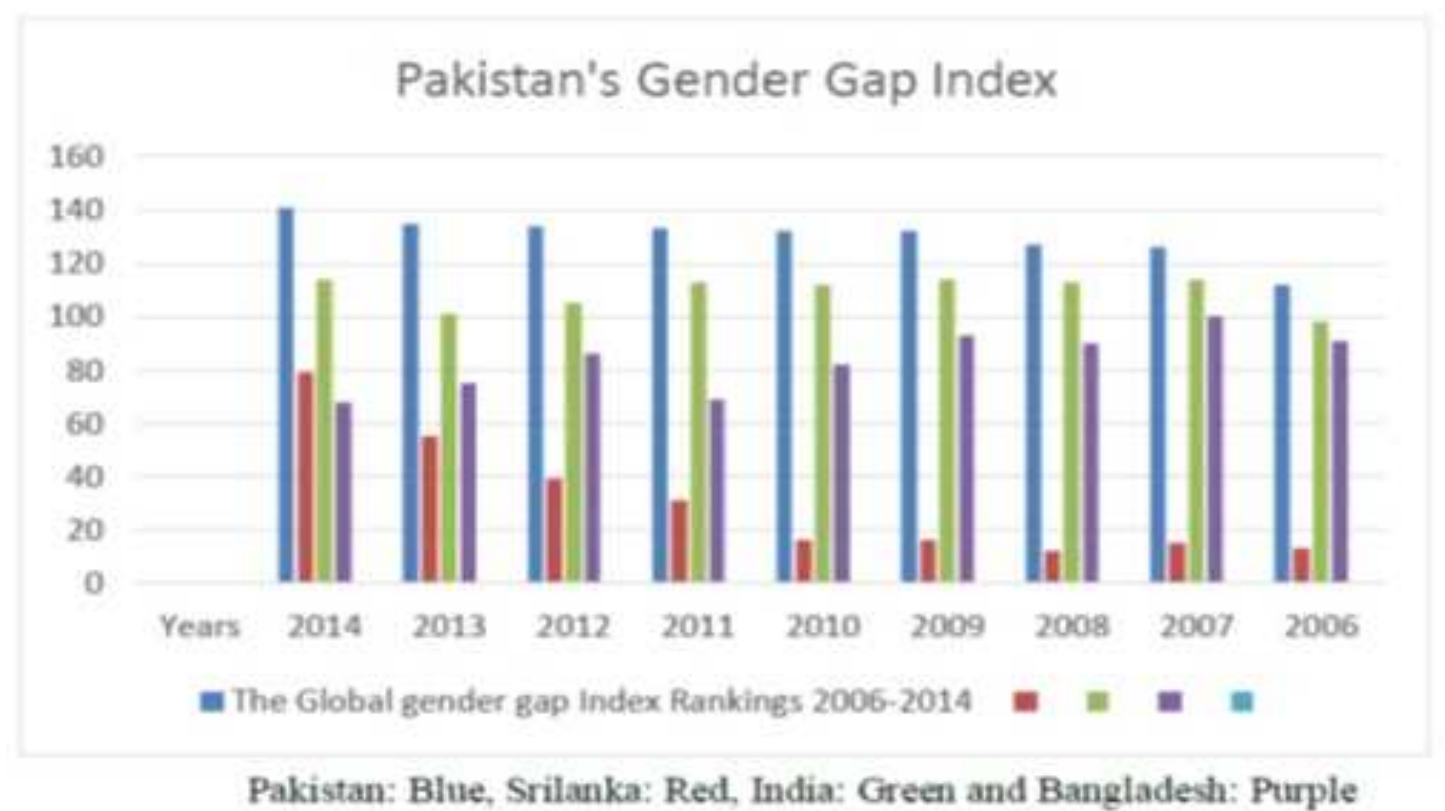

Figure 1.Gender gap Index of Pakistan by Sharjeel Saleem et al., (2017)

Sharjeel Saleem et al., (2017) researched the Glass Ceiling and found the presence of glass ceiling, particularly characterizing its effects on the selection and promotion of the female candidates and their effectiveness. The authors found that glass ceiling was negatively related to both female effectiveness and "selection and promotion." This is significant evidence to support that the organizational policies do not favor women managers.

Ismail (2012)revealed that women are unable to progress in the field of journalism as they are too conscientious about things like justice, correctness, and balance; they do not take risks. In other words, the internal organizational structures do not support women managers. Ahmad and Naseer (2018) showed that in the private and public organizations of Pakistan, women are being paid less in comparison to men in the same position. They also revealed that Glass Ceiling exists more for the graduate level qualified women in comparison to M. Phil and 
Ph.D. qualified women. Females come across more problems in comparison to males, including the glass ceiling (Hoobler et al., 2011). Taste-based discrimination theory suggests that labor market discrimination is a phenomenon in which the discrimination is done while hiring and promotion activities based on preferences of management instead of merit. The preferences can be based on internal organizational policies (Becker, 2009). In the context of Pakistan, currently, the status of the glass ceiling is alarming. The females are subjected to the phenomenon of glass ceiling (Ismail, 2012; Saleem et al., 2017). Therefore, based on the literature review and substantial empirical evidence, the following hypothesis is proposed.

Hypothesis: Social Internal Structure of the Organization is attributed to Glass Ceiling at Federal Chartered Universities of Pakistan

\section{Material and Methods}

\section{Population}

Out of all Federal Chartered Universities of Pakistan, 21 universities are in Islamabad and Rawalpindi, which is $70 \%$ of the total Federal Chartered Universities of Pakistan. These universities have six thousand four hundred and fifty-five faculty members at the time of this research. All faculty members were the population of the study.

\section{Sampling Design}

Non-probability sampling design was used in this research. In the current research, the data was collected in two phases. The first phase is the higher stage, while the second phase was the lower stage of the data collection. At the higher stage, the convenience sampling was used, and at a lower stage, purposive sampling was used. The purposive sampling was chosen to consider the possible influence of gender on the primary variable of the research, and purposive sampling was used to maintain a similar percentage of the gender.

\section{Sample Size}

According to Israel (2009), the recommended sample from the population of six thousand four hundred and fifty-five faculty members, is three hundred (325). However, the researcher distributed a total of six hundred and fifty questionnaires. Four hundred and eighty-four(484) usable questionnaires from respondents were received, showing the response rate of seventy-four point five $(74.5 \%)$.Data was collected from the employees of the Federal chartered universities.

\section{Instrumentation}

The instrument has three main sections. The first part covers the demographics of the respondents. One of the critical items from the demographics section of the instrument was about the gender of the respondent. Further to it, the 
demographic section also included information related to respondents age and experience in academia.

The second section of the instrument was adapted from Smith, Crittendne, and Caputi (2012). It was based on a five-point Likert Scale ranging from Strongly Disagree to Strongly Agree. One of the sample items of the questionnaire was, "Women managers suffer more emotional pain than men when there is a crisis within their teams."

To find the reasons for the glass ceiling in Federal chartered universities of Pakistan, the relevant questions were asked in the form of discussion questions. As the result of which deep insight into the reasons for the glass ceiling was found and was incorporated in the final questionnaire distributed for data collection.

\section{Reliability}

The reliability of a questionnaire was measured through internal consistency using the value of Cronbach alpha. The value of Cronbach alpha measures the internal consistency of items, which shows how closely a set of items are related in a group (Cortina, 1993). The results of Cronbach's alpha showed that the questionnaire has an excellent internal consistency (Cronbach Alpha, 0.814). This value is considered adequate by Nunnally (1994) for the reliability of the scale.

\section{Pilot Testing and Validation}

The pilot testing was conducted in the Federal chartered universities, which were then excluded from the sample. The content validation and face to face validation step was performed with seven academicians in the area of human resource management and education. The face validation step was performed with 5 Ph.D. scholars and two consultants. As a result, the changes were incorporated. Changes were incorporated in the questionnaire, as per the recommendations of the academic experts, practitioners, and statistical results. The questionnaire was finalized after expert opinion and pilot testing. The questionnaire was used for data collection from the male and female faculty members. The pilot testing had been done initially for forty (40) responses from the sample. Forty responses are considered adequate for pilot testing, as 10-13 responses are considered enough for pilot testing (Hill, 1998; Isaac \& Michael, 1995; van Belle, 2002). It was observed that the results obtained as the result of the pilot testing were satisfactory, and no problem was found, suggesting that the choice of words and sentence structure was right and fitted well in the context. The participants of the focus group were asked to give their reflections on each of the items.

\section{Data Collection}

The data was collected through a questionnaire using a survey-based technique. The questionnaire was distributed and collected by the researcher herself 
and through contacts. The respondents were first elaborated on the purpose and need of the research. The respondents were explained different sections of the questionnaire and were asked to be as candid and truthful as they could while responding. They were also ensured that the data collected will be used for research purposes only and the anonymity of the respondents.

Through the data collected, statistical analysis was conducted, and the results were drawn. To further confirm the findings through the questionnaire and establishing the qualitative aspect of the study, discussions were conducted. They revealed the aspects that helped the research in knowing the factors and also the techniques to melt the glass ceiling. The recommended sample from the population of six thousand four hundred and fifty-five faculty members is three hundred (325). However, the researcher received four hundred and eighty-four (484) usable questionnaires from respondents.

\section{Data Analysis}

\section{Demographics}

The descriptive analysis showed that there were $50 \%$ female respondents and $50 \%$ male respondents. The gender percentage remained $50 \%$ for each gender, mainly because purposive sampling was used. Since the number of females in jobs is lesser than the number of males in Pakistan. Therefore, given the nature of the research study, the percentage of the respondents was kept $50 \%$ for each gender purposefully. Experience is one of the critical factors in the glass ceiling. Approximately $75 \%$ of the respondents had experience less than 20 years. The rest of the $25 \%$ of the respondents were having experience higher than 20 years. However, none of the respondents had experience of more than 30 years.

\section{Tests of Normality}

To apply different statistical tests, the data must be normal. To find if the data is normal or otherwise, necessary tests of normality, such as skewness and kurtosis were applied, the results of the tests indicated that the values of Skewness and Kurtosis were well within the range. The value of skewness should be between -1.00 to +1.00 , and that of Kurtosis should be between -3.00 to +3.00 for data to be considered normal. In this case, the value of skewness and kurtosis fall well within the range. Therefore, the data is found to be normal and parametric tests can be applied.

\section{Existence of Glass Ceiling}

To achieve the objectives of the research, it was pertinent to know about the existence of Glass Ceiling in Federal chartered universities of Pakistan. To ascertain the existence of glass ceiling, a one-sample t-test was applied. 
One sample t-test is a parametric test that is used to determine whether the mean of the observed values is statistically different from a hypothesized or known mean. The following table represents shown the value when the hypothesized mean or population mean, or the test value was taken as 3 .

Table 1

One-Sample Statistics

\begin{tabular}{lllll}
\hline & $\mathrm{N}$ & Mean & Std. Deviation & Std. Error Mean \\
\hline Glass Ceiling & 484 & 3.3816 & .78442 & .03566 \\
\hline
\end{tabular}

Table 2. One-Sample Test

\begin{tabular}{lcccc}
\hline & & & \multicolumn{2}{c}{ Test Value $=3$} \\
& $\mathrm{t}$ & Df & Sig. (2-tailed) & $\begin{array}{c}\text { Mean } \\
\text { Difference }\end{array}$ \\
\hline Glass Ceiling & 10.704 & 483 & .000 & .38164 \\
\hline
\end{tabular}

Results of glass ceiling study are reported in the above table. Glass ceiling for the observed values, at the .05 level of significance, was statistically different and higher than the hypothesized mean value of 3 .

One sample t-test results indicate that glass ceiling exists in the observed value since the mean value of the sample is statistically different from that of the hypothesized mean value of 3 , as shown in Table 1 and Table 2. Thus, the existence of glass ceiling in Federal chartered universities of Pakistan was confirmed. Once the existence of glass ceiling was ascertained, the analysis was done for other research objectives. This confirmed our first hypothesis and we failed to reject the hypothesis that the Glass Ceiling exists in the Federal Chartered Universities of Pakistan.

\section{Gender Biases, Social Internal Structure, and Glass Ceiling}

The responses were noted. To meet the above research objective, the descriptive statistics was used; as a result the following table was generated

Table 3

Elements of Glass Ceiling

\begin{tabular}{ccc}
\hline & & Total \\
\hline \multirow{3}{*}{ Reasons GC } & Gender Biases & 341 \\
\cline { 2 - 3 } & Social Internal Struc. Of Org. & 139 \\
\cline { 2 - 3 } & Any other & 42 \\
\hline & Total Respondents & 522 \\
\hline
\end{tabular}

As a result of the analysis, Gender Biases and Social Internal Structure of Organization were found to be elements of the glass ceiling in the Federal chartered universities of Pakistan. 
The data revealed that gender biases as the top element of glass ceiling as perceived by $65 \%$ of employees of Federal chartered universities of Pakistan. $27 \%$ of the employees of the perceived social internal structure of the organization as the second top element of the glass ceiling in Federal chartered universities of Pakistan, followed by eight employees who considered "self-pity," "resilience problems," "personality problems," and "low output at workplace" etc. are few of the other reasons as shown in Table 3. Since the common element of the glass ceiling could not be ascertained in these factors, thus its aggregate percentage falls below any other. Therefore, it has been ranked as last. The data confirmed our hypothesis and we fail to reject the hypothesis. Thus, Gender Biases and Social internal structures of an organization are attributed to the phenomenon of the glass ceiling in Federal Chartered Universities of Pakistan.

\section{Strategies to melt the Glass Ceiling}

During the focused group discussions following suggestions were presented and discussed to melt the glass ceiling. Following strategies came forward for melting the glass ceiling:

a. Human Resources should be hired and promoted to the next level based on talent and potential. There should not be different angles of assessing the human resource for males and females. For unmarried women, it is presumed that they will leave the job after getting married. This presumption about women must not be considered for hiring.

b. If women are young and newly married, it is assumed that she will be taking maternity leave soon, and the working of the office will then be affected, so in many cases, they are not being hired. This issue should be resolved by giving an excellent daycare center facility to the working women.

c. There is no denying that women have an essential role to play in the family and housekeeping. This must not be taken against the women as a lack of interest and dedication in the job; instead, this problem should be resolved by giving them the facility of flexible working hours.

d. Ones in a while, they should be given the facility of work from home as well.

\section{Results and Discussions}

\section{Summary}

The glass ceiling is a well-known phenomenon, however, in Pakistan, the phenomenon is relatively new, and literature in this context is very scarce. This research was an endeavor to fill this gap. The purpose of this research was to find out if the glass ceiling exists in federal chartered universities of Pakistan. The 
research objectives were accordingly derived. To achieve this, the data was collected from the university employees using the survey method, and one sample t-test was employed. It was found that the glass ceiling exists in the Federal chartered institutes of Pakistan. The analysis revealed that different elements of glass ceiling existed in Federal chartered universities of Pakistan, which were based on gender biases and the internal social structure of organizations. It has been found that the gender-based glass ceiling has been perceived as the most followed by the perceived social internal structure of the organization as the top element of the glass ceiling. Our findings confirm the literature that different elements of the glass ceiling exist in organizations both in the manufacturing sector and service sector(Levine \& D'Agostino, 2018; Nandy et al., 2014; Powell, 2018; Thams et al., 2018).

The discussions with the respondents confirmed the findings based on the quantitative data, which was also supported by earlier empirical evidence (Akhtar, 1996; Al-Khalifa, 1990; Deem, 2005; Limerick et al., 1995; Walsh \& Morley, 2005; Williams, 2005).Therefore, the findings of this research are in line with the earlier research, which indicates that the elements of the glass ceiling exist in the higher education sector.

The internal structure of organizations also hinders women from being recruited. Such organizations have gender biases, culture that set against women, and lack of career advancement opportunities for women(Johns, 2013; Linnabery et al., 2014; Snaebjornsson et al., 2015). This is in line with the findings of our research in which the data indicate that organizational structural barriers exist. The research objective to find the strategies to melt the elements of the glass ceiling was achieved through the discussion with the respondents. The strategies have been discussed earlier in the analysis portion of this research.

\section{Conclusion and Discussion}

In the research, it is concluded that the glass ceiling exists in the Federal chartered universities of Pakistan. It was further found that the glass ceiling based on gender and internal social structures of the organizations are factors of the glass ceiling in the Federal chartered universities of Pakistan. Women are too less in number at the workplace due to prejudice, unfairness, and inequality in treatment with them(Weyer, 2007). Working women face stereotypes of discrimination due to which they face hindrance in career advancement(Crosby et al., 2004), they are not being provided with an opportunity to lead the organization simply because they were women. Working women needed some individual facilities for the continuation of the job and to be more dedicated and devoted. Especially working mothers need special facilities like proper daycare centers and medical facilities. Data revealed that both were lacking in the federal chartered universities of Pakistan. Whether the Day Care centers were not there and if it were provided, it was just a room. She was responsible for the maid of the child. This lack of facility sometime caused the end of a career or lack of devotion and attention towards the 
job. Proper Daycare centers with doctor and teacher with the availability of primary educational needs should be provided to working women. The nature of Glass Ceiling may differ from country to country, but its existence cannot be denied. In Pakistan, women are deprived and underrepresented just because they are women (Siraj \& Sadiq, 2016). This means that Pakistan has a gender bias. The same has been supported by the theory of taste of discrimination (Becker, 2101). The findings are in line with the theory according to which the marginalized persons, either of gender, race, or color, are subject to "special treatment," such as the glass ceiling.

\section{Recommendations and Research Implications}

In the light of the findings and the data collected on the existence of glass ceiling in the federal chartered universities of Pakistan following are the recommendations, 1) For gender biases objective-based awareness program related to inclusiveness should be launched, 2) For the internal structure of an organization quota should be fixed for the women. Different factors that lead to the glass ceiling in the higher education sector of Pakistan should be addressed as per the strategies provided to melt the glass ceiling. The recruitment, selection, and promotion boards of the federal charter universities of Pakistan should be inclusive and free from bias to decide on merit only. The strategies to melt the glass ceiling in the federal chartered unvisited of Pakistan, should be an eye-opener for the policymakers and the HR departments of the universities.

\section{Future Recommendations}

Glass Ceiling in the Federal Chartered Universities of Pakistan opens up many avenues for further research. It is recommended that beside federal chartered universities, the research can be conducted in other provinces of the country. Further, a comparative study of glass ceiling with other countries can be done. The same research can be conducted at the other levels of educational institutions,e.g., higher secondary schools and degree awarding institutions. 


\section{References}

Akhtar, S. (1996). Do girls have a higher school drop-out rate than boys? A hazard rate analysis of evidence from a Third World city. Urban Studies, 33(1), 49-62.

Al-Khalifa, E. (1990). Equal Opportunities for Women: Attitudes and Practices in Education. Women in Management Review, 5(5).

Anh, T. T. T. (2018). Investigating the gender wage gap in Vietnam by quantile regression: Sticky floor or glass ceiling. Journal of Economic Development, JED, Vol. 25 (S01), 4-23.

Arulampalam, W., Booth, A. L., \& Bryan, M. L. (2007). Is there a glass ceiling over Europe? Exploring the gender pay gap across the wage distribution. ILR Review, 60(2), 163-186.

Barnet-Verzat, C., \& Wolff, F.-C. (2008). Gender wage gap and the glass ceiling effect: A firm-level investigation. International Journal of Manpower, 29(6), 486502.

Becker, G. S. (1993). Nobel lecture: The economic way of looking at behavior. Journal of Political Economy, 101(3), 385-409.

Becker, G. S. (1996). The Economic Way of Looking at Behavior. Hoover Institution, CA: Stanford University.

Becker, G. S. (2009). Human capital: A theoretical and empirical analysis, with special reference to education. University of Chicago press.

Becker, G. S. (2010). The economics of discrimination. University of Chicago press.

Booysen, L. A., \& Nkomo, S. M. (2010). Gender role stereotypes and requisite management characteristics: The case of South Africa. Gender in Management: An International Journal, 25(4), 285-300.

Bosse, D. A., \& Taylor III, P. L. (2012). The second glass ceiling impedes women entrepreneurs. The Journal of Applied Management and Entrepreneurship, 17(1), 52.

Boyd, K. S. (2008). Glass ceiling. Encyclopedia of Race, Ethnicity, and Society, 549-52.

Byrd, M. Y. (2009). Telling our stories of leadership: If we don't tell them they won't be told. Advances in Developing Human Resources, 11(5), 582-605.

Cardoso, A. R., \& Winter-Ebmer, R. (2010). Female-led firms and gender wage policies. ILR Review, 64(1), 143-163. 
Carnes, M., Morrissey, C., \& Geller, S. E. (2008). Women's health and women's leadership in academic medicine: Hitting the same glass ceiling? Journal of Women's Health, 17(9), 1453-1462.

Commission, F. G. C. (1995). Good for business: Making full use of the nation's human capital: A fact-finding report of the Federal Glass Ceiling Commission. US Government Printing Office.

Cook, A., \& Glass, C. (2014). Above the glass ceiling: When are women and racial/ethnic minorities promoted to CEO? Strategic Management Journal, 35(7), 1080-1089.

Cortina, J. M. (1993). What is coefficient alpha? An examination of theory and applications. Journal of Applied Psychology, 78(1), 98.

Crosby, F. J., Williams, J. C., \& Biernat, M. (2004). The maternal wall. Journal of Social Issues, 60(4), 675-682.

Davidson, M. (2009). The glass ceiling-Australian and British women in management 2009: Myth or reality. 44th Australian Psychological Society Annual Conference.

Deem, R. (2005). Power and resistance in the academy: The case of women academic managers. In Transforming Managers (pp. 81-98). Routledge.

Eagly, A. H., \& Carli, L. L. (2007). Through the labyrinth. Boston, MA: Harvard Business School Press.

Fortin, N. M. (2005). Gender role attitudes and the labour-market outcomes of women across OECD countries. Oxford Review of Economic Policy, 21(3), 416-438.

Hill, R. (1998). What sample size is "enough" in internet survey research. Interpersonal Computing and Technology: An Electronic Journal for the 21st Century, 6(3-4), 1-12.

Hoobler, J. M., Lemmon, G., \& Wayne, S. J. (2011). Women's underrepresentation in upper management: New insights on a persistent problem. Organizational Dynamics, 40(3), 151-156.

Isaac, S., \& Michael, W. B. (1995). Handbook in research and evaluation: Educational and Industrial Testing Services. San Diego, CA.

Ismail, U. (2012). Concept of "Glass Ceiling" in the Print Media of Pakistan. The Journal of the South East Asia Research Centre, 2, 69-77. 
Israel, G. D. (2009). Determining sample size. University of Florida Cooperative Extension Service, Institute of Food and Agriculture Sciences, EDIS. http://zulsidi.tripod.com/pdf/DeterminingSampleSizes.pdf

Japan taps on glass ceiling, asking for more female lawmakers. (n.d.). Nikkei Asian Review. Retrieved September 16, 2018, from https://asia.nikkei.com/Politics/Japan-taps-on-glass-ceiling-asking-for-morefemale-lawmakers

Johns, M. L. (2013). Breaking the glass ceiling: Structural, cultural, and organizational barriers preventing women from achieving senior and executive positions. Perspectives in Health Information Management/AHIMA, American Health Information Management Association, 10(Winter).

Khanna, S. (2012). Gender wage discrimination in India: Glass ceiling or sticky floor?

Kim, S., Kim, J.-D., Shin, Y., \& Kim, G.-H. (2015). Cultural differences in motivation factors influencing the management of foreign laborers in the Korean construction industry. International Journal of Project Management, 33(7), 15341547. https://doi.org/10.1016/j.ijproman.2015.05.002

Levine, H., \& D'Agostino, M. J. (2018). A Global Comparison Of Women In The Workforce. In Governing in a Global World (Vol. 19, pp. 19-32). ROUTLEDGE in association with GSE Research.

Limerick, B., Heywood, E., \& Ehrich, L. C. (1995). Women-only Management Courses: Are they appropriate in the 1990s? Asia Pacific Journal of Human Resources, 33(2), 81-92.

Linnabery, E., Stuhlmacher, A. F., \& Towler, A. (2014). From whence cometh their strength: Social support, coping, and well-being of Black women professionals. Cultural Diversity and Ethnic Minority Psychology, 20(4), 541.

Lockwood, N. (2004). The glass ceiling: Domestic and international perspectives. Citeseer.

Maginn, P. J. (2010). Breaking through the glass ceiling of local government. The Gender Profile Of, 4.

Mathur-Helm, B. (2006). Women and the glass ceiling in South African banks: An illusion or reality? Women in Management Review, 21(4), 311-326.

Nandy, S., Bhaskar, A., \& Ghosh, S. (2014). Corporate glass ceiling: An impact on Indian women employees. International Journal of Management and International Business Studies, 4(2), 135-140. 
Ng, E. S., \& Sears, G. J. (2017). The glass ceiling in context: The influence of CEO gender, recruitment practices and firm internationalisation on the representation of women in management. Human Resource Management Journal, 27(1), 133-151.

Northouse, P. G. (2018). Leadership: Theory and practice. Sage publications.

Nunnally, J. C. (1994). Psychometric theory 3E. Tata McGraw-Hill Education.

Parker, B., \& Fagenson, E. A. (1994). An introductory overview of women in corporate management. Women in Management: Current Research Issues, 11-30.

Powell, G. N. (2018). Women and men in management. Sage Publications.

Saleem, S., Rafiq, A., \& Yusaf, S. (2017). Investigating the glass ceiling phenomenon: An empirical study of glass ceiling's effects on selection-promotion and female effectiveness. South Asian Journal of Business Studies, 6(3), 297-313.

Siraj, I. T., \& Sadiq, I. A. (2016). Synthesis, characterization and antimicrobial activities of a Schiff base derived from phenylalanine and acetylacetone and its Mn (II), Ni (II) and Cu (II) complexes. ChemSearch Journal, 7(2), 34-39.

Smith, P., Crittenden, N., \& Caputi, P. (2012). Measuring women's beliefs about glass ceilings: Development of the Career Pathways Survey. Gender in Management: An International Journal, 27(2), 68-80.

Snaebjornsson, I. M., Edvardsson, I. R., Zydziunaite, V., \& Vaiman, V. (2015). CrossCultural leadership: Expectations on gendered leaders' behavior. SAGE Open, 5(2), 2158244015579727.

Still, L. V. (2006). Where are the women in leadership in Australia? Women in Management Review, 21(3), 180-194.

Tan, J. (2008). Breaking the "bamboo curtain" and the "glass ceiling": The experience of women entrepreneurs in high-tech industries in an emerging market. Journal of Business Ethics, 80(3), 547-564.

Thams, Y., Bendell, B. L., \& Terjesen, S. (2018). Explaining women's presence on corporate boards: The institutionalization of progressive gender-related policies. Journal of Business Research, 86, 130-140.

Valian, V. (1998). Why so slow. Cambridge, Ma: MIT Press.

van Belle, G. (2002). Do not dichotomize unless absolutely necessary. Statistical Rules of Thumb. New York: John Wiley E Sons, 99-100.

Venkataravanappa, K. (n.d.). Women in Global Leadership. 
Walsh, V., \& Morley, L. (2005). Breaking boundaries: Women in higher education. Taylor \& Francis.

Weyer, B. (2007). Twenty years later: Explaining the persistence of the glass ceiling for women leaders. Women in Management Review, 22(6), 482-496.

Williams, J. C. (2005). The glass ceiling and the maternal wall in academia. New Directions for Higher Education, 2005(130), 91-105. 